Y/EN- 8311

December 2009

\title{
Comparison of the NDA of HEU Oxide between the AWCC and the HPGe Detector
}

\author{
Lisa Chiang \\ Rick Oberer \\ Cynthia Gunn \\ Elaine Dukes \\ Andy Akin
}

\author{
Prepared by the \\ Y-12 National Security Complex \\ P.O. Box 2009, Oak Ridge, Tennessee 37831-8169 \\ Managed by \\ BWXT Y-12, L.L.C. \\ for the \\ U.S. DEPARTMENT OF ENERGY \\ under contract DE-AC05-00OR22800
}




\section{Disclaimer}

This report was prepared as an account of work sponsored by an agency of the United States Government. Neither the United States Government nor any agency thereof, nor any of their employees, makes any warranty, express or implied, or assumes any legal liability or responsibility for the accuracy, completeness, or usefulness of any information, apparatus, product, or process disclosed, or represents that its use would not infringe privately owned rights. Reference herein to any specific commercial product, process, or service by trade name, trademark, manufacturer, or otherwise, does not necessarily constitute or imply its endorsement, recommendation, or favoring by the United States Government or any agency thereof. The views and opinions of authors expressed herein do not necessarily state or reflect those of the United States Government or any agency thereof. 
Y/EN- 8311

December 2009

\section{Abstract}

This paper compares the performance of the Active Well Coincidence Counter (AWCC) with the performance of high resolution gamma spectrometry using an HPGe detector to nondestructively assay highly enriched (HEU) oxide. ${ }^{1}$ Traditionally the AWCC was considered to be the more appropriate instrument for this measurement. Although the AWCC had a high degree of precision, the HPGe provided the more accurate measurement of this material. The AWCC determines mass of U-235 from the coincident pairs of neutron detections, or doubles rate. The HPGe determines the mass of both U-235 and U238, the enrichment, and the quantity of other radioisotopes. The Tl208 gamma rays were used to verify the amount of attenuation for the HPGe analysis. ${ }^{2}$

Fifty-four cans of enriched $\mathrm{U}_{3} \mathrm{O}_{8}$ were shipped to the $\mathrm{Y}-12$ National Security Complex from Los Alamos National Laboratory (LANL) under Scrap Declaration LANL-45. ${ }^{3}$ The declared values for net weight, mass of uranium, mass of U-235, and enrichment (percent mass of U-235 to total uranium) are shown in Table A-1. The masses of U-235 range from $104 \mathrm{~g}$ to $2404 \mathrm{~g}$ and the enrichment varies from $20 \%$ to $98 \%$.

\section{Theoretical considerations}

The purported advantage of the AWCC is the penetrability of neutrons compared to gamma rays. This advantage is called "purported" because we have not seen an actual study of this penetrability for the AWCC measurement. The penetrability depends on both the depth distribution of the induced fissions in the material which give rise to coincident neutron detections, and the probability of detecting the coincident neutron from the fission. Furthermore, this advantage is over the penetrability of the $186 \mathrm{keV}$ gamma rays from U-235. The comparison should consider the penetrability of higher energy gamma rays from Tl-208 which we use to augment gamma assays.

The disadvantages of the AWCC can be divided into two categories. ${ }^{4}$ First the AWCC measurement is fundamentally limited to one (doubles) or at best two (doubles and triples) output parameters to solve a substantial number of unknowns. Second, the theoretical parameters (unknown) are not easily determined from observable, physical characteristics of the material. These physical characteristics are mass of U-235, density, chemical and isotopic composition, and geometry including container shape and location of the container within the well. The theoretical parameters are induced fission rate,

\footnotetext{
${ }^{1}$ Presented at the INMM Central Regional Chapter,2009 Fall Meeting, Oak Ridge, Tennessee, November 3-4, 2009.

${ }^{2}$ R. B. Oberer, L. G. Chiang, M. J. Norris, C. A. Gunn, and D. R. Eblen. Determination of uranium concentration and attenuation correction in dense highly enriched uranium (HEU) material by the comparison of gamma rays from Tl-208. In Proceedings of the Institute of Nuclear Materials Management 49th Annual Meeting, July 13-17, 2008, Nashville, Tennessee.

R. B. Oberer, L. G. Chiang, M. J. Norris, C. A. Gunn, and B. C. Adaline, The use of Tl-208 gamma rays for safeguards, nondestructive-assay (NDA) measurements. Technical Report, Y/EN-8270, Y12 National Security Complex, May 2009.

${ }^{3}$ SCRAP DECLARATION LANL-45, Nuclear Material Control and Accountability Shipper/Receiver Agreement between Los Alamos National Laboratory and the Y-12 National Security Complex for Highly Enriched Uranium Oxides, February 26, 2009.

${ }^{4}$ N. Ensslin, B. Geist, M. Krick, and M. Pickrell, “Active Neutron Multiplicity Counting,” LA-UR-071403, Chapter 7, Passive Nondestructive Assay of Nuclear Materials, 2007 Addendum.
} 
Y/EN- 8311

December 2009

coupling, multiplication, and neutron detection efficiency among others. These theoretical parameters depend of the physical characteristics in complicated ways. For example, it has been observed that the doubles rate can change as much as $15 \%$ from a $5 \mathrm{~cm}$ change in the sample height within the well of the item being measured, ${ }^{5}$ yet none of the theoretical parameters can be predicted based on this height.

Passive gamma measurements, on the other hand, provide numerous gamma ray energies which can be used to determine unknown theoretical parameters. Whereas the AWCC can determine mass of U-235 at best, a gamma measurement can determine the quantity of U-235, U-238, isotopic composition as well as the quantity of other radioactive isotopes. Furthermore the effects on theoretical parameters such as geometry, and attenuation are easily estimated from observable physical characteristics such as density, composition, shape of the container and measurement distance.

Because of these differences, only the intrinsic detection efficiency of the detector is determined from the calibration for a gamma-ray measurement. In this case a mixed isotope source, containing no uranium, was used to produce an efficiency calibration as a function of gamma ray energy. Because of the complexity of the AWCC the calibration takes account of all factors that perturb the measurement. Therefore the calibration standards must be representative of the assay items and must span these items in all the physical characteristics affecting the measurement.

\section{$\underline{\text { Results }}$}

The measurement results for both the AWCC and the HPGe instruments are presented in detail in Table A-1 as an appendix. The results for the mass of U-235 for both the AWCC and HPGe measurements are summarized in Figure 1. These measurements were performed as a Nuclear Material Control and Accountability (NMC\&A) confirmation measurement. Therefore, in addition to the measured values, the values determined by the shipper are also available. The shipper's values are referred to as the declared values.

\footnotetext{
${ }^{5}$ N. Ensslin, M. S. Krick, W. C. Harker, M. C. Miller, R. D. McElroy, P. A. McClay, W. L. Belew, R. N. Ceo, L. L. Collins, and P. K. May, “Analysis of Initial In-Plant Active Neutron Multiplicity Measurements,” Los Alamos National Laboratory report LA-UR-93-2631, Proc. 34th Annual INMM Meeting, Scottsdale, AZ, July 18-21, 1993.
} 
Y/EN- 8311

December 2009

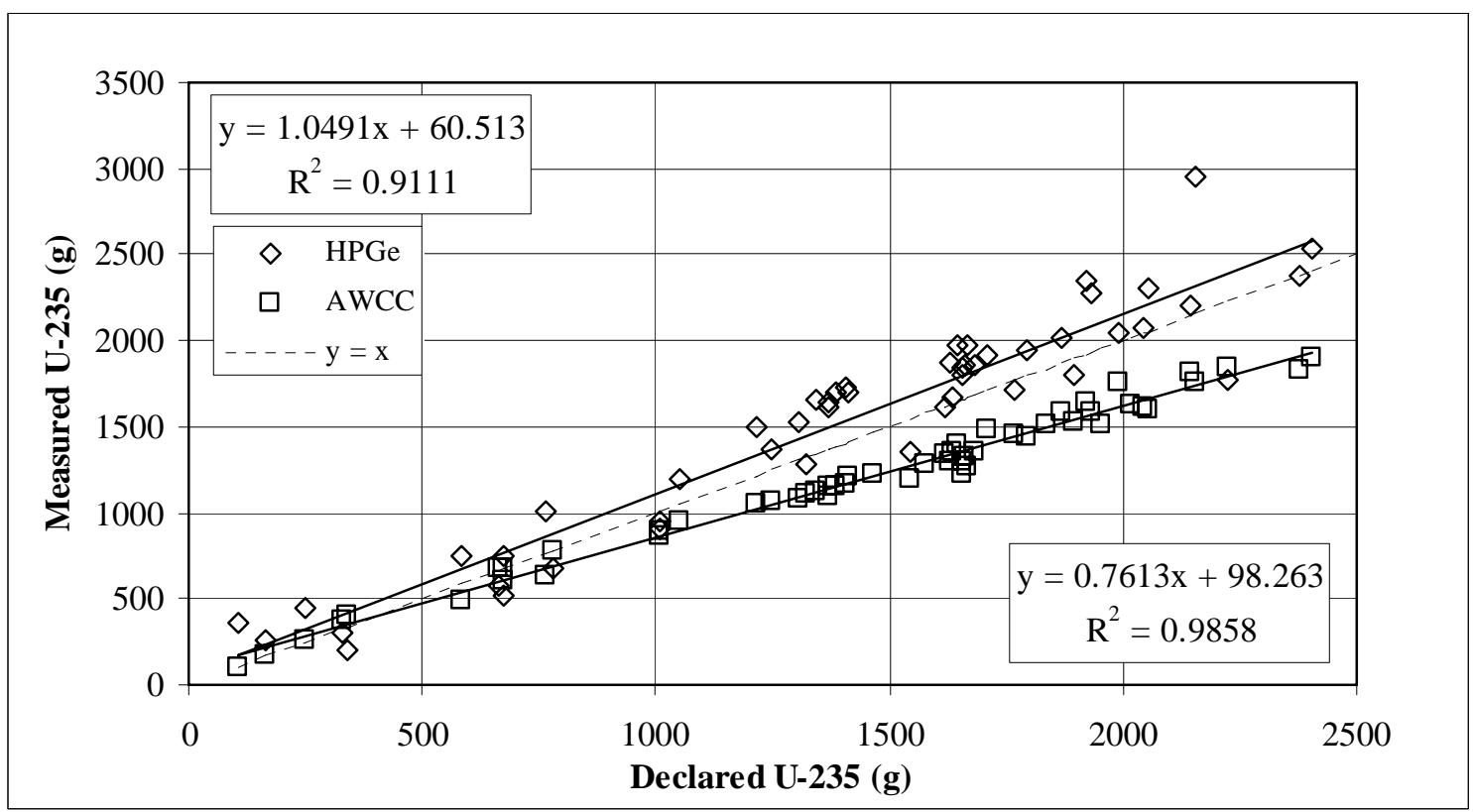

Figure 1: Results of the measurement of the mass of U-235 compared to declared values for both the AWCC and the HPGe.

The least squares fit to both sets of data in also shown in Figure 1. The fit to the HPGe results is 1.05 times the declared value, and there is a small $60 \mathrm{~g}$ positive offset. The fit to the AWCC results is 0.76 of the declared value with a $98 \mathrm{~g}$ positive offset. Although there is a significant bias in the AWCC results, it is highly correlated to the declared values.

There are two outliers in the HPGe results. One has a declared value of $2157 \mathrm{~g} \mathrm{U}-235$ and was measured at $2950 \mathrm{~g} \pm 610 \mathrm{~g} \mathrm{U}-235$. The measurement is 1.3 standard deviations above the declared value. The other has a declared value of $2226 \mathrm{~g} \mathrm{U}-235$ and was measured at $1770 \mathrm{~g} \pm 366 \mathrm{~g} \mathrm{U}-235$. The measurement is 1.25 standard deviations below the declared value. 
Y/EN- 8311

December 2009

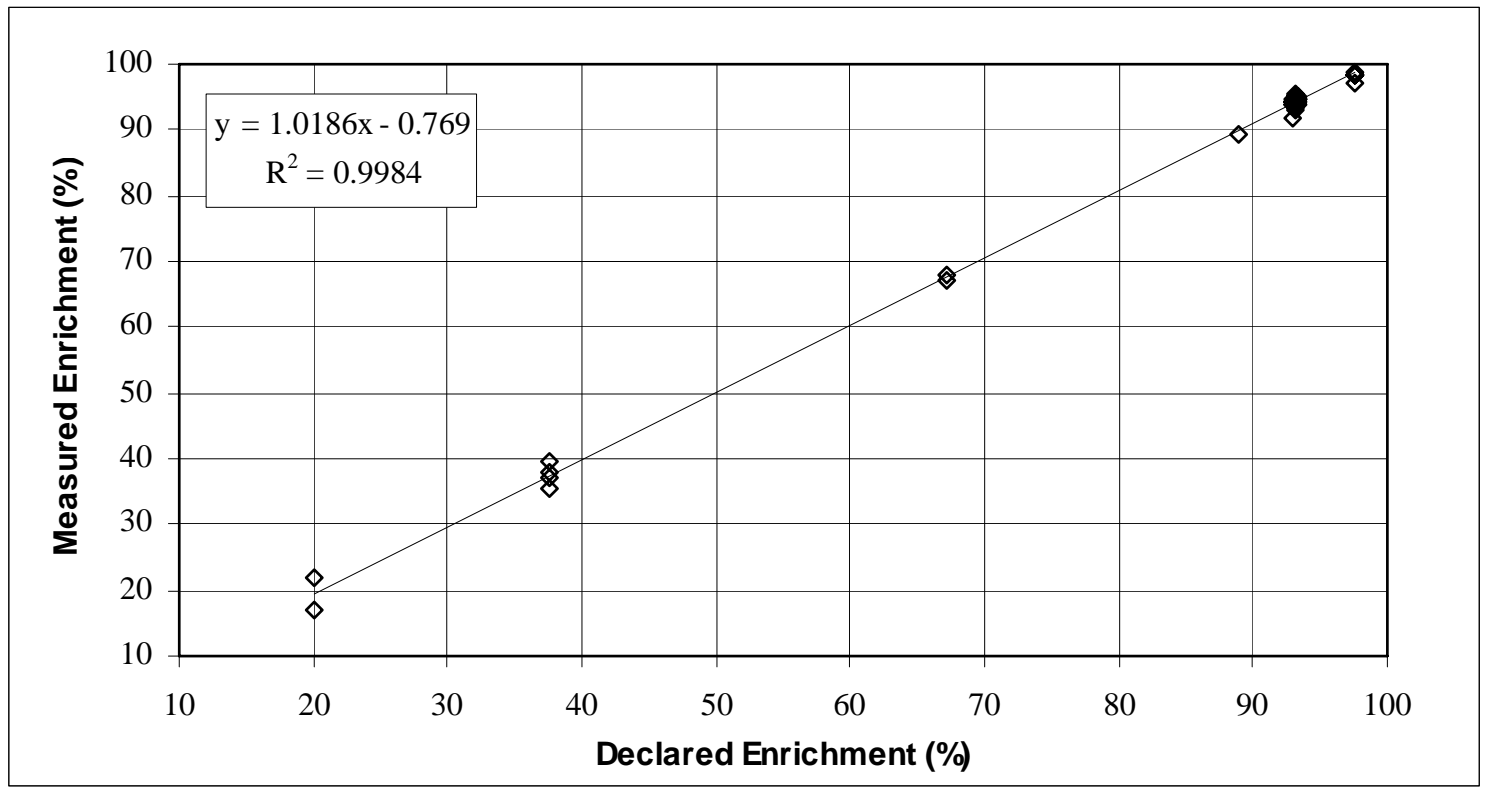

Figure 2: Results of the enrichment (weight percent of U-235 mass) measured by the HPGe.

In addition to the mass of U-235, the HPGe measurements provide enrichment data. The enrichment results from the HPGe detector are shown in Figure 2. There are five groups of declared enrichments from $20.5 \%$ to $97.66 \%$. In addition, there was one can declared to be $89 \%$ enriched. The shipper's declared values confirm with a great deal of confidence based on the HPGe measurement alone. The HPGe masses were measured within $5 \%$ and the enrichments were measured within $2 \%$ of the declared values.

In addition to the mass of U-235 and U-238, the HPGe also measures the quantity of other radioactive isotopes. Several of the items were found to have elevated Cs-137 levels. This isotope is a relatively long lived fission product, indicating that some of the material has been irradiated in a reactor. 
Y/EN- 8311

December 2009

\section{Calibration of the AWCC}

The AWCC was calibrated with Set\#3 of 93.18\% enriched $\mathrm{U}_{3} \mathrm{O}_{8}$, New Brunswick Laboratory, Certified Reference Material 149 (CRM-149). ${ }^{6}$ For both the calibration and measurement, the AWCC was operated with the cadmium liner (but no nickel liner) and without the bottom, polyethylene plug . Furthermore, the cans were positioned on top of the 4-inch metal stand placed at the bottom of the sample well in the AWCC. This stand was in place for both the calibration and subsequent measurement.

Table 1 shows the calibration curve used by the AWCC for measuring the LANL-45 receipts. $D$ is the doubles rate and $m$ is the mass of $U-235$. The covariance matrix is also shown.

Table 1. Calibration Curve for the AWCC used for LANL-45 receipts.

\begin{tabular}{|c|c|c|c|c|c|}
\hline \multicolumn{6}{|c|}{ Equation: $D=\mathrm{a}+\mathrm{b} * m+\mathrm{c} * m^{2}+d * m^{3}$} \\
\hline & Value & \multicolumn{4}{|c|}{ Covariance matrix } \\
\hline & & $\mathrm{a}$ & $\mathrm{b}$ & c & $\mathrm{d}$ \\
\hline a: & $4.1263 \mathrm{E}+00$ & $1.00 \mathrm{E}+01$ & $-2.41 \mathrm{E}-02$ & 1.50E-05 & $-2.66 \mathrm{E}-09$ \\
\hline b: & 2.0220E-01 & & 8.29E-05 & $-5.96 \mathrm{E}-08$ & $1.14 \mathrm{E}-11$ \\
\hline c: & $-3.3843 \mathrm{E}-05$ & & & 4.67E-11 & $-9.37 \mathrm{E}-15$ \\
\hline $\mathrm{d}:$ & 4.3494E-09 & & & & $1.93 \mathrm{E}-18$ \\
\hline
\end{tabular}

The curve below the CRM-149 calibration in Figure 3 is a hypothetical calibration which would produce results closest to the LANL-45 declared values. This curve was produced from the LANL-45 material with declared values as the calibration standard.

\footnotetext{
${ }^{6}$ Certified Reference Material 149, Report on Production and Characterization, New Brunswick Laboratory report CRM-149 Final, (not dated).
} 
Y/EN- 8311

December 2009

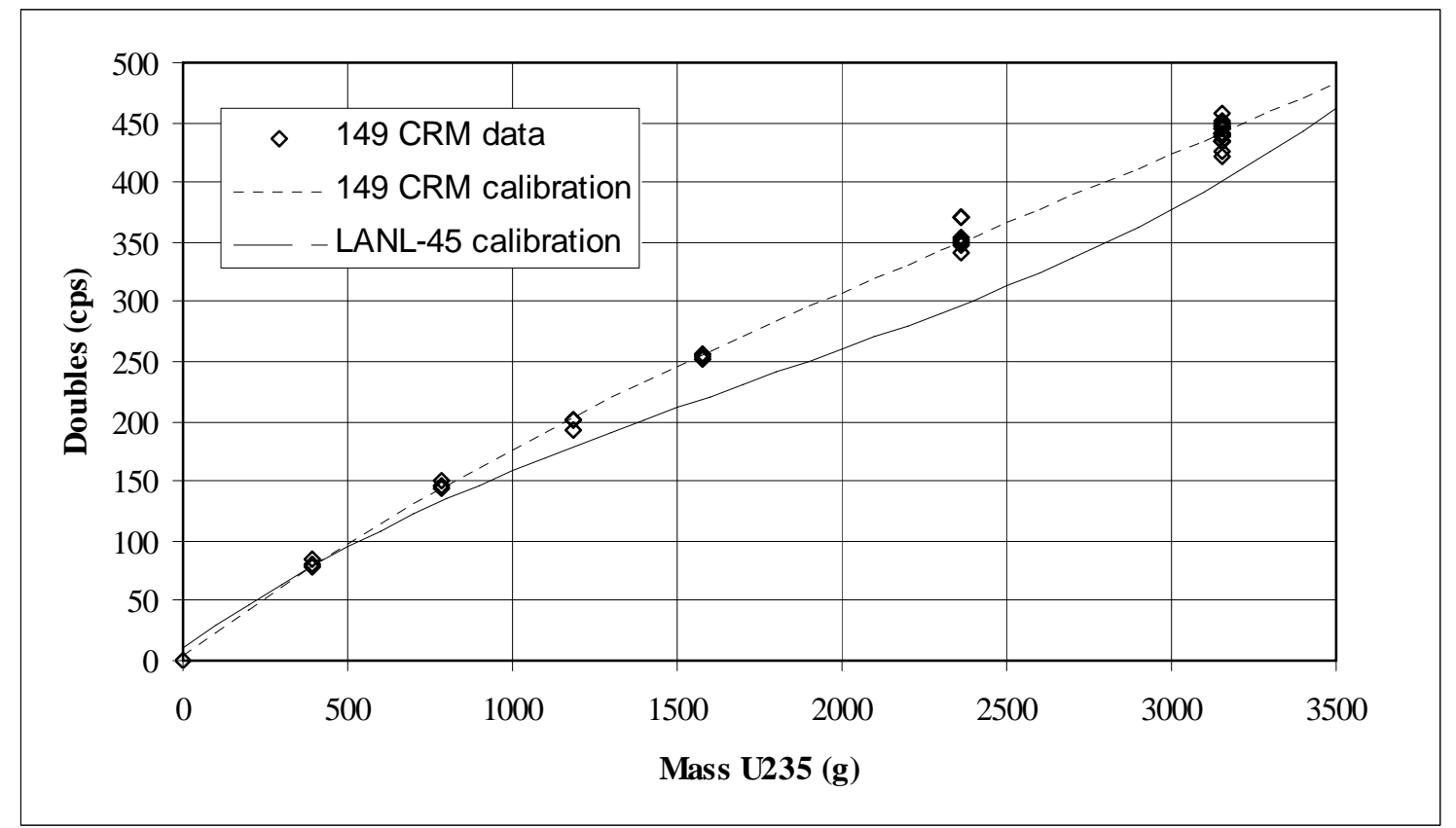

Figure3: Comparison of calibration curves for the AWCC. The top curve is the CRM-149 calibration with actual data points. The bottom curve is the calibration which would result using the LANL-45 material as standards.

The certified values CRM-149 is shown in Table 2. Using the NBL nomenclature, the Description field in the first column is encoded as follows: the first number indicates the Set \#, the second number is the nominal enrichment, the third number is the chemical composition, and the last number is the nominal mass of the sample in grams.

Table 2. Masses of uranium in CRM-149, Set \#3.

\begin{tabular}{|l|l|l|l|l|l|}
\hline Description & $\begin{array}{l}\text { Sample } \\
\text { Weight } \\
\text { (g) }\end{array}$ & $\begin{array}{l}\text { Gross } \\
\text { Weight } \\
(\mathrm{kg})\end{array}$ & $\begin{array}{l}\text { Tare } \\
\text { Weight } \\
(\mathrm{kg})\end{array}$ & $\begin{array}{l}\text { Net } \\
\text { Weight } \\
(\mathrm{kg})\end{array}$ & $\begin{array}{l}\text { U-235 } \\
(\mathrm{g})\end{array}$ \\
\hline 3_93_U308_500 & 500 & 0.7420 & 0.2420 & 0.5000 & 393.79 \\
\hline 3_93_U308_1000 & 1000 & 1.2458 & 0.2458 & 1.0000 & 787.74 \\
\hline 3_93_U308_1500 & 1500 & 1.7453 & 0.2453 & 1.5000 & 1181.62 \\
\hline 3_93_U308_2000 & 2000 & 2.2436 & 0.2436 & 2.0000 & 1575.49 \\
\hline 3_93_U308_3000 & 3000 & 3.2436 & 0.2435 & 3.0001 & 2363.31 \\
\hline 3_93_U308_4000 & 4000 & 4.2423 & 0.2421 & 4.0002 & 3151.13 \\
\hline 3_93_blank & blank & & & 0 & 0 \\
\hline
\end{tabular}


Because the effect of the factors previously discussed, the doubles rate measured by the AWCC is not easily predicted. Therefore, the unknown material must be the same type of material (enrichment, density, chemical composition, and form factor) as the standards, in a similar size and type of container as the standards, and then measured at the same height in the AWCC as the standards. A comparison of the physical makeup of the CRM-149 calibration standards and the LANL-45 material is shown in Figure 4. The differences are a single can versus a double can, a polyethylene bag, and the diameter of the container. There is no simple theory to predict the effect of these differences. The metal container is thought to be irrelevant to the neutron measurement. The polyethylene in the plastic bag is believed to increase the doubles rate which slightly increases the reported mass. The decreased diameter of the LANL-45 can must reduce the coupling between the AmLi neutron source and the material. The reduced coupling is consistent with the negative bias in the result.

CRM-149

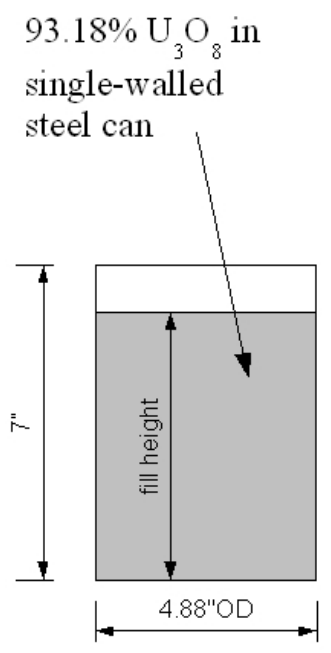

LANL-45

fill height $\sim 1.417 " \% \mathrm{~kg}$ 20 to $98 \%$ enriched $\mathrm{U}_{3} \mathrm{O}_{8}$ in bagged,
inner convenience can, inside
outer convenience can

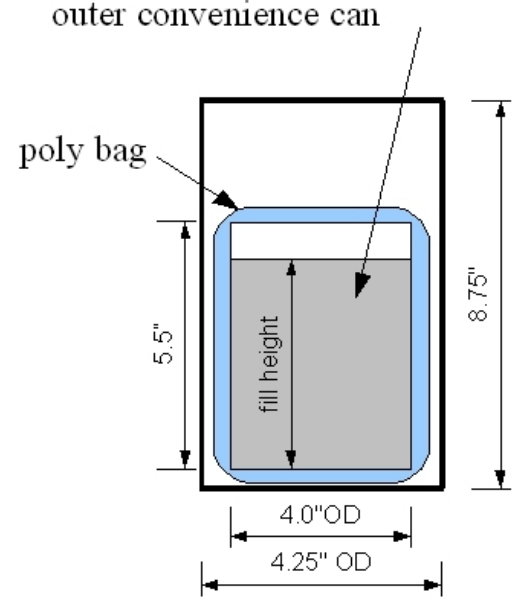

fill height $\sim 1.94 " / \mathrm{kg}$

Figure 4: Comparison of the physical configuration of the CRM-149 calibration standards with the LANL-45 material.

Of the fifty-four items, forty of them were at very nearly 93\% enrichment. See Figure 2 for the distribution of enrichments among the items. Restricting to AWCC plot in Figure 1 to only those cans matching the 93\% enrichment of the calibration standards does not substantially improve the results. The curve fit for the $93 \%$ items is $m_{\text {AWCC }}=0.781 \cdot m_{\text {Dec }}+62.4 \mathrm{~g}$. Therefore, the differences in enrichments do not explain the bias in the AWCC measurement. 
Y/EN- 8311

December 2009

\section{AWCC Measurement Control}

During calibration and throughout the LANL-45 receipt measurements, the CRM-149 4kg standard (3_93_U308_4000) was run in the AWCC as a quality control. This standard has a mass of U-235 of 3151.13g. The masses reported by the AWCC for all of these runs are shown below in Figure 5. The first 20 runs were from the initial control measurements. The last set of runs (Run \#21 through Run \#38) was measured during the LANL-45 receipt measurements. These runs demonstrate that the AWCC remained within measurement control throughout both the calibration measurements and throughout the receipt measurements.

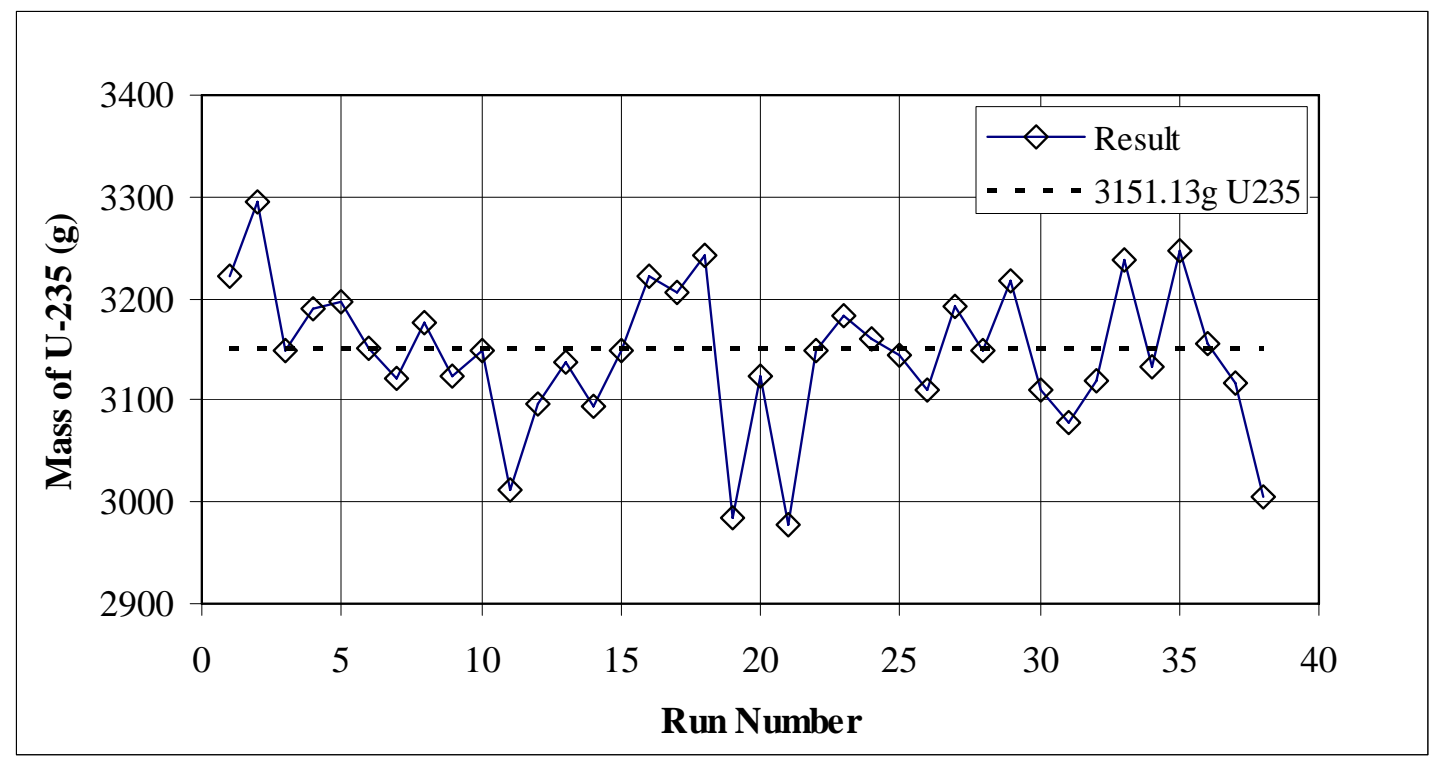

Figure 5: Mass reported by AWCC for the 4 kg CRM-149 control standard (3_93_U308_4000) during calibrations and LANL-45 receipts. The dotted line represents the U-235 content of the control standard.

One standard deviation from the first 20 runs of the control chart is approximately 63g of $\mathrm{U}-235$ from a 10 minute measurement time. The mean value of all of the control runs is $3153 g$ of U-235.

\section{HPGe method}

Two 50\% efficient HPGe detectors were used to perform the LANL-45 measurements. The spectra were analyzed using ISOTOPIC ${ }^{7}$ software. The same heavy-duty collimator was used with both detectors. This collimator provides one inch of collimation.

A far-field geometry was used. This geometry is shown in Figure 6. The standoff was set to 24 inches as shown. The height was at the center of the inner can. The items were rotated on a turntable.

\footnotetext{
${ }^{7}$ ORTEC ISOTOPIC Supervisor and Operator, Program for Radioactive Waste Characterization, ISOPLUS-B32 Software User's Manual (2 Volumes).
} 
Y/EN- 8311

December 2009

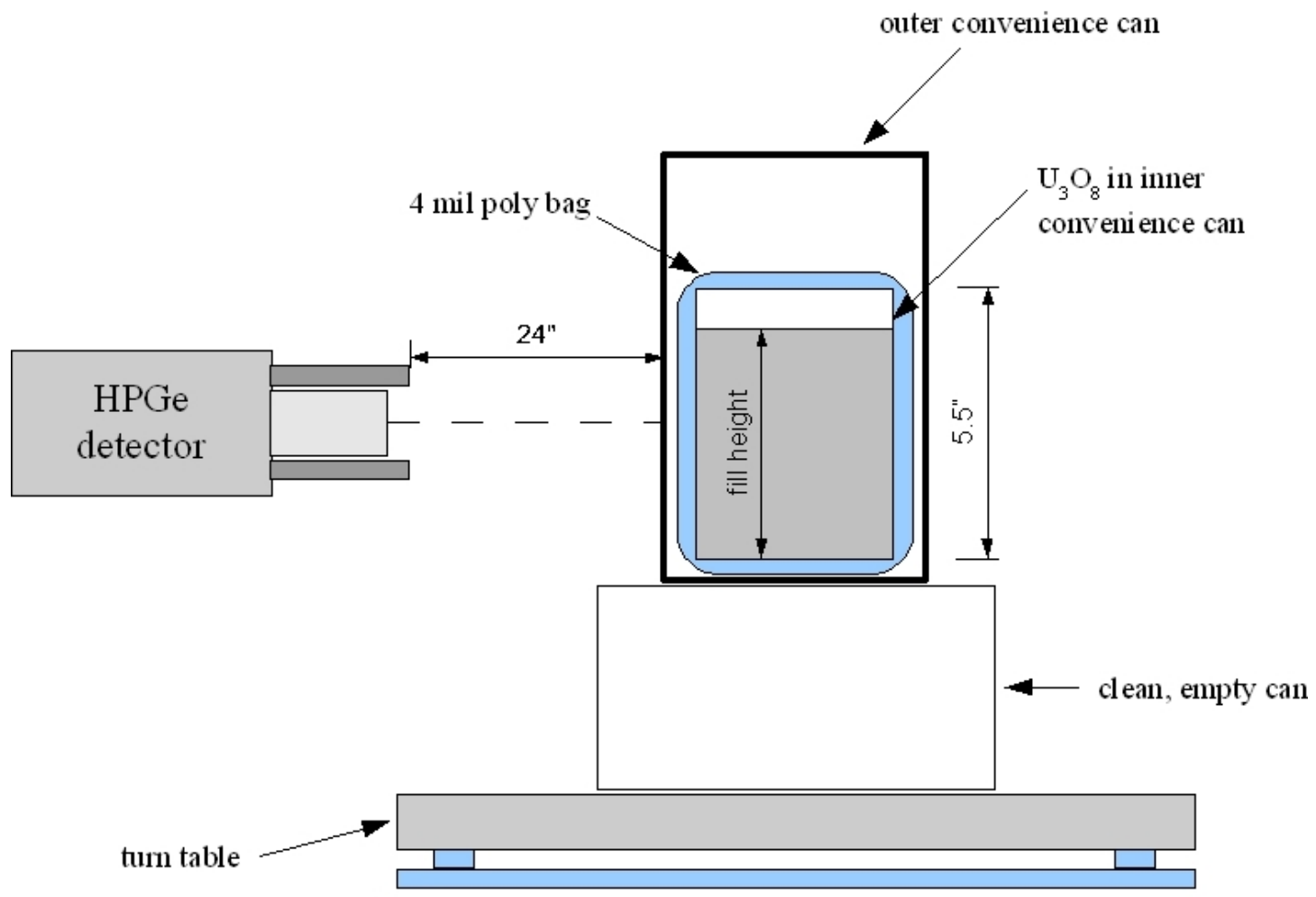

Figure 6: HPGe measurement configuration and geometry for LANL-45 cans.

\section{Calibration of the HPGe}

The calibration of the HPGe detector is fundamentally different than the calibration of the AWCC. Only the intrinsic detection efficiency is determined in the calibration of the HPGe. Therefore, the representativeness of the calibration standard is in the energy of the gamma rays produced by the standard. These gamma rays are shown in Table 3 . The range of the calibration is from $60 \mathrm{keV}$ to $1800 \mathrm{keV}$. It is also important to have sufficient gamma rays in the knee of the efficiency curve around $150 \mathrm{keV}$. This intrinsic efficiency is actually an absolute efficiency, without attenuation, at $30 \mathrm{~cm}$.

The efficiency calibration for one of the detectors will now be discussed as an example. The efficiencies for each energy, as shown in Table 3, are used to fit the intrinsic efficiency curve of Equation 1. The values for the coefficients is shown in Table 4. These efficiency points along with the curve from Equation 1 are shown in Figure 7. 
Y/EN- 8311

December 2009

Table 3. Gamma-ray energies from the mixed isotope calibration source and respective detection efficiencies.

\begin{tabular}{|c|c|}
\hline $\begin{array}{c}\text { Energy } \\
E \\
(\mathrm{keV})\end{array}$ & $\begin{array}{c}\text { Efficiency } \\
\varepsilon_{i} \\
(\%)\end{array}$ \\
\hline 59.54 & $5.90 \mathrm{E}-04$ \\
\hline 88.03 & $1.87 \mathrm{E}-03$ \\
\hline 122.07 & $2.41 \mathrm{E}-03$ \\
\hline 165.85 & $2.51 \mathrm{E}-03$ \\
\hline 279.17 & $1.79 \mathrm{E}-03$ \\
\hline 391.69 & $1.34 \mathrm{E}-03$ \\
\hline 661.62 & $8.40 \mathrm{E}-04$ \\
\hline 898.02 & $6.63 \mathrm{E}-04$ \\
\hline 1173.24 & $5.39 \mathrm{E}-04$ \\
\hline 1332.5 & $4.74 \mathrm{E}-04$ \\
\hline 1836.06 & $3.68 \mathrm{E}-04$ \\
\hline
\end{tabular}

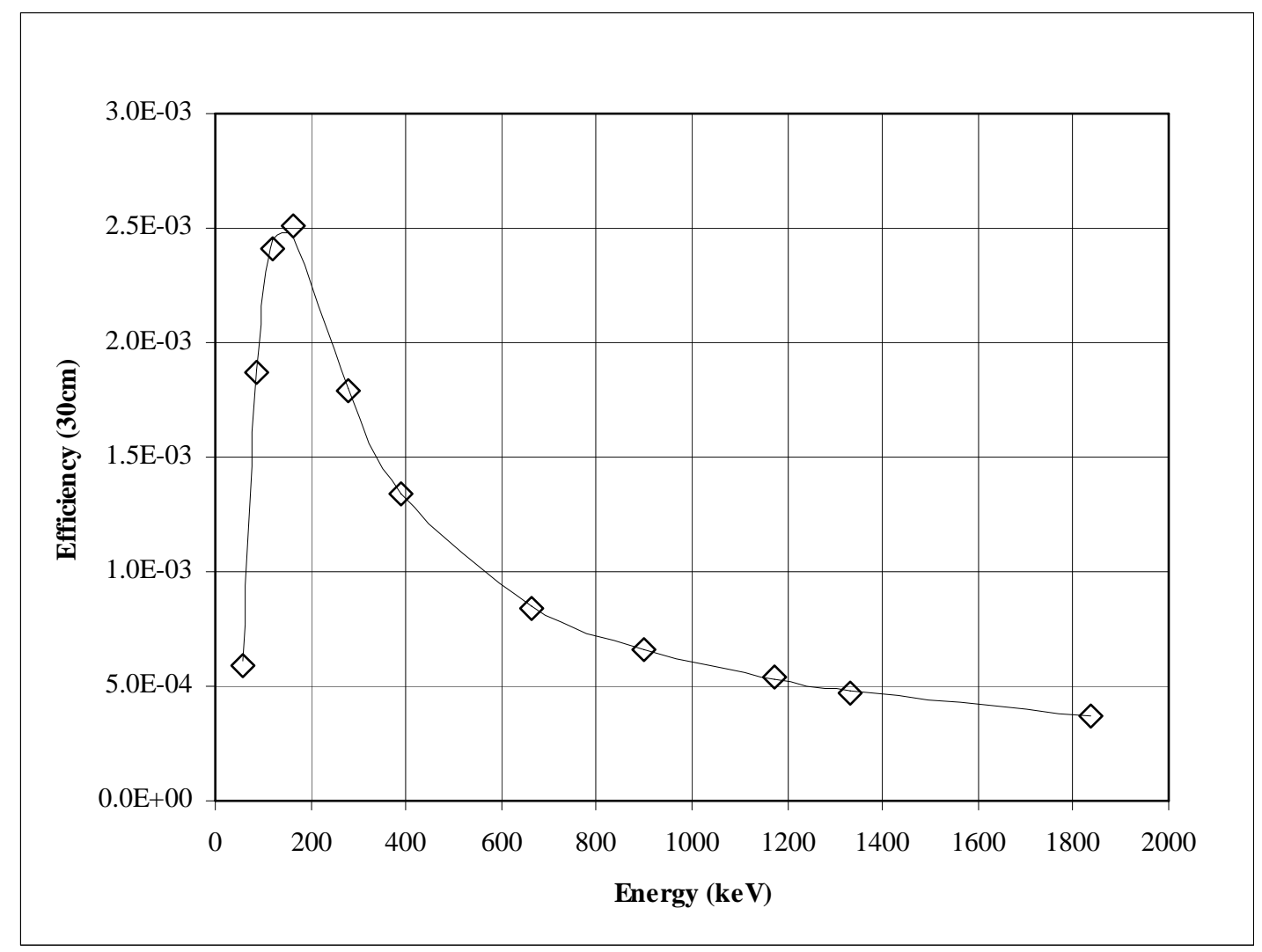

Figure 7. Intrinsic detection efficiency of gamma rays over the calibrated energy range for detector 48-TP32008B. 
Y/EN- 8311

December 2009

Table 4. Coefficients for Equation (1) for the intrinsic efficiency curve shown in Figure 7.

\begin{tabular}{|c|r|}
\hline Coefficient & Value \\
\hline $\mathrm{a}_{1}$ & -0.29764 \\
$\mathrm{a}_{2}$ & -7.69393 \\
$\mathrm{a}_{3}$ & 0.658792 \\
$\mathrm{a}_{4}$ & -0.08543 \\
$\mathrm{a}_{5}$ & 0.004615 \\
$\mathrm{a}_{6}$ & -0.00011 \\
\hline
\end{tabular}

$$
\varepsilon_{i}=e^{a_{1} E+a_{2}+a_{3} E^{-1}+a_{4} E^{-2}+a_{5} E^{-3}+a_{6} E^{-4}}
$$

Equation (1)

In addition to the intrinsic efficiency, which is determined from the calibration, the effects of container attenuation, matrix attenuation, and geometry are calculated from the physical description of the unknowns. Attenuation depends on material composition, density and thickness. Geometry depends on distance to the detector. The term matrix as used here includes the uranium and the material it is mixed with.

\section{Gamma Measurement of CRM-149 Material}

As an experiment of the gamma measurement method, the CRM-149 standards were measured as unknowns. The model used for these measurements is shown in Figure 8. The documentation for the CRM-149 standards, stated that the fill height of the oxide in the standards is 1.417 inches per $\mathrm{kg}$ of net weight. This fill height implies a density of about $2.4 \mathrm{~g} / \mathrm{cc}$. 
Y/EN- 8311

December 2009

Top View

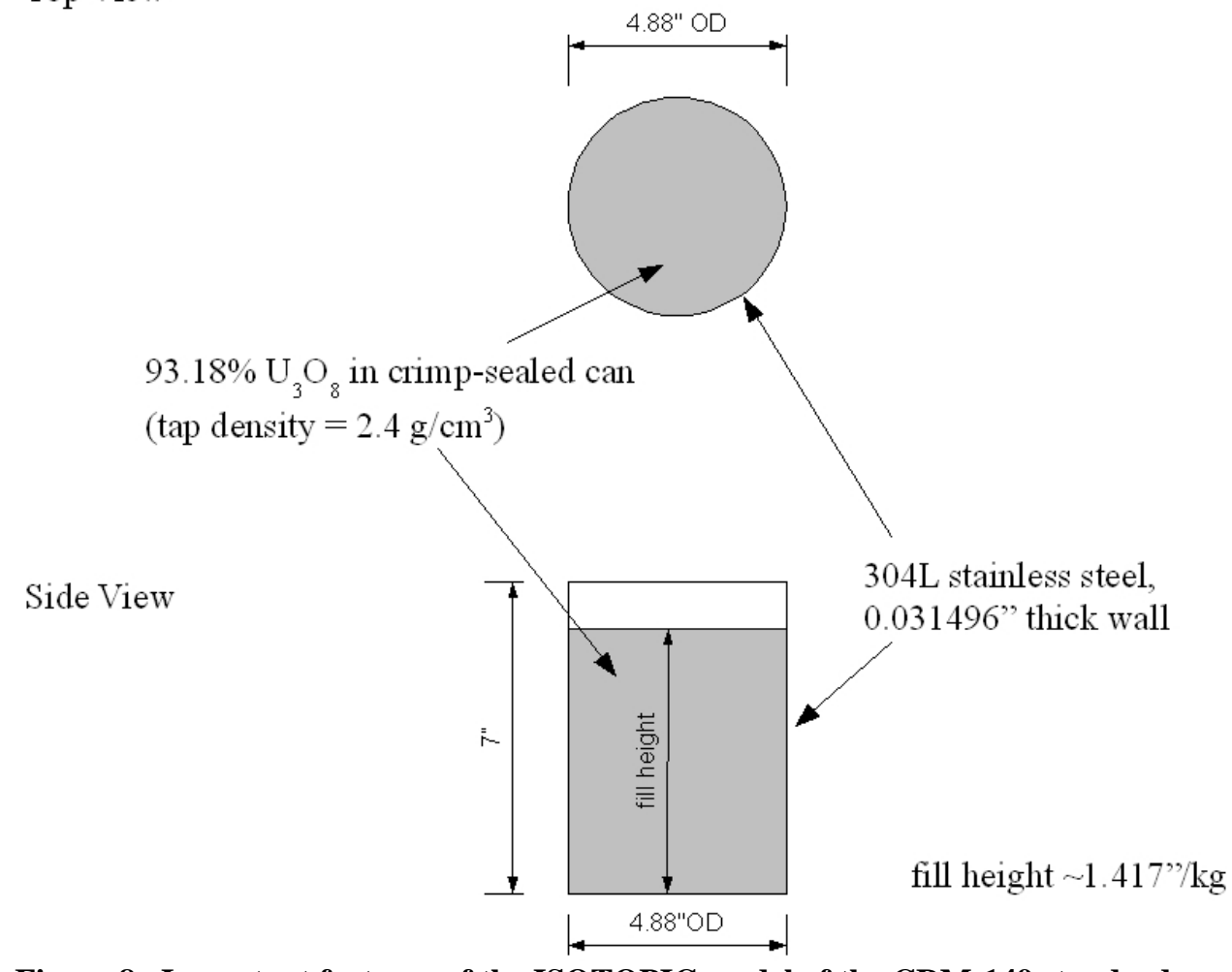

Figure 8. Important features of the ISOTOPIC model of the CRM-149 standards.

The results based on this density and fill height are shown in Figure 9 as "Theoretical" (square markers). Although these results are highly correlated with the true values, they are biased high. The spectra were reanalyzed using the Tl-208 gamma rays to adjust the density of the uranium oxide matrix. These results are also shown in Figure 9 as "Diff attn" (diamond markers). The results become very accurate using differential attenuation on the Tl-208 gamma rays. However, some random uncertainty is introduced by the adjustment. The random error might be the result of making the adjustments subjectively. An objective method might produce less random error. 


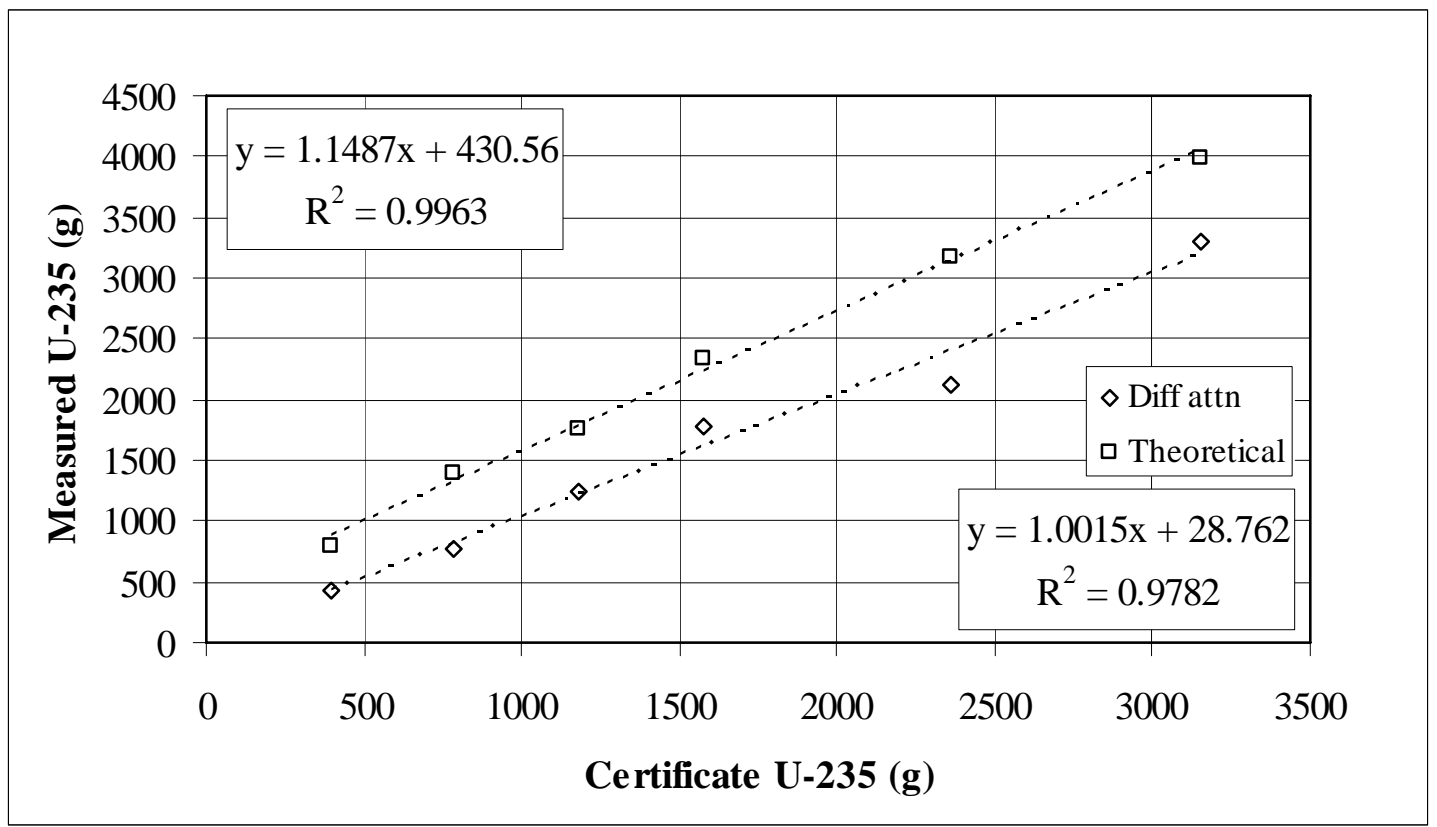

Figure 9. Result of the HPGe measurement of the CRM-149 standards. The results based on the theoretical density and fill height are shown in top curve labeled as "Theoretical” (square markers). The results from differential attenuation on the Tl-208 gamma rays are shown in the bottom curve labeled "Diff attn" (diamond markers).

The densities used to calculate the matrix attenuation is shown in Table 5. The fill height and density from the CRM-149 documentation is shown in columns three and four of the table. The density resulting in the best differential attenuation of the Tl-208 peaks is shown in the last column.

Table 5. List of CRM-149 standards from Set 3 showing the fill height and density from the documentation (1.417 inches/kg) and the effective density resulting from the application of differential attenuation.

\begin{tabular}{|c|r|r|r|r|}
\hline Description & \multicolumn{1}{|c|}{$\begin{array}{c}\text { Net weight } \\
\text { (g) }\end{array}$} & \multicolumn{1}{|c|}{$\begin{array}{c}\text { Fill height } \\
\text { (in) }\end{array}$} & $\begin{array}{c}\text { Density } \\
\text { without } \\
\text { diff attn } \\
\text { (g/cc) }\end{array}$ & $\begin{array}{c}\text { Density } \\
\text { with } \\
\text { diff attn } \\
\text { (g/cc) }\end{array}$ \\
\hline 3_93_U308_500 & 500 & 0.71 & 2.49 & 1.32 \\
\hline 3_93_U308_1000 & 1000 & 1.42 & 2.44 & 1.31 \\
\hline 3_93_U308_1500 & 1500 & 2.13 & 2.42 & 1.67 \\
\hline 3_93_U308_2000 & 2000 & 2.83 & 2.42 & 1.81 \\
\hline 3_93_U308_3000 & 3000 & 4.25 & 2.41 & 1.59 \\
\hline 3_93_U308_4000 & 4000 & 5.67 & 2.40 & 1.95 \\
\hline
\end{tabular}

In reality it is the density thickness $\rho x$ that describes the attenuation. Therefore, the resulting density cannot be taken entirely literally. The thickness is the diameter of the can. In addition, ISOTOPIC considers the average distance parallel to the diameter for cylinders. 
Y/EN- 8311

December 2009

\section{ISOTOPIC Models}

The ISOTOPIC model of the LANL-45 cans is shown in Figure 10. The inner and outer cans were treated as a single container with a thickness of 0.03 inches. The fill height was set at 1.94 inches per kg of net weight. The estimated density of the contents was then corrected using the differential attenuation analysis where the effective matrix density is adjusted to minimize the difference in the reported Tl-208 activities calculated using the $583 \mathrm{keV}$ and $860 \mathrm{keV}$ gamma rays. ${ }^{8}$

Top View

4.25" OD, 8.75" tall

Outer Convenience Can

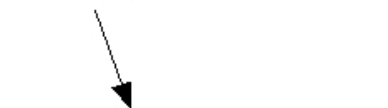

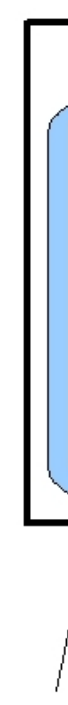

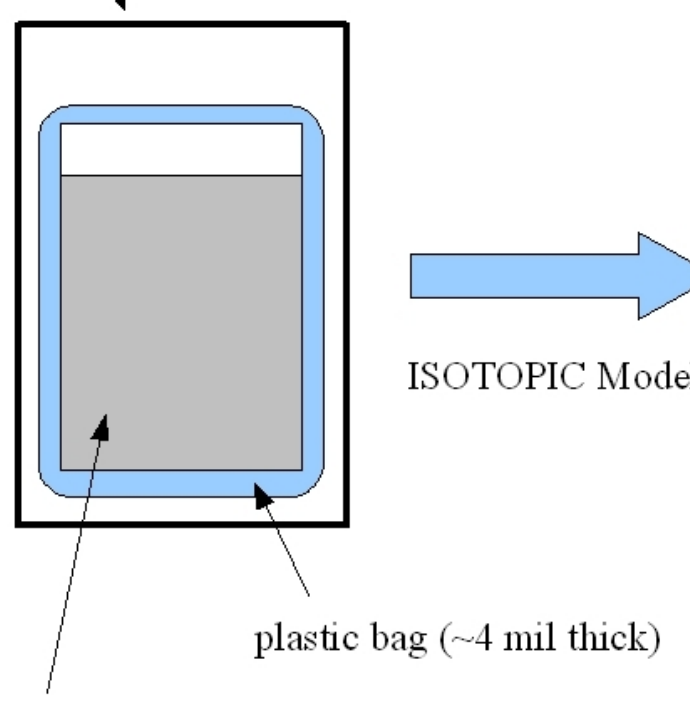

$\mathrm{U}_{3} \mathrm{O}_{8}$ inside 4 " OD, 5.5" tall

Inner Convenience Can

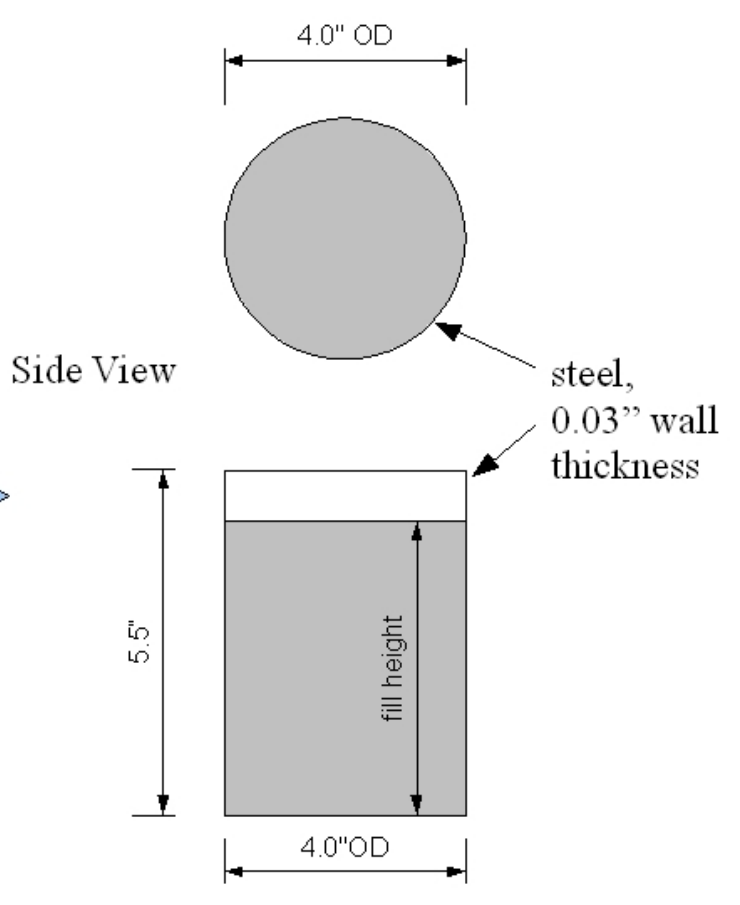

fill height $\sim 1.94 \% / \mathrm{kg}$

Figure 10: ISOTOPIC model for the LANL-45 containers. The inner and outer convenience cans were collapsed into a single container. The fill height was set to 1.94 inches per $\mathrm{kg}$ of net weight.

\section{Improvement and Alternative Gamma Measurements}

An alternative approach for a gamma-ray measurement would be a U-235 and U-238 concentration measurement. The effects of geometry could be eliminated by a very narrow collimator and keeping the field of view of the detector filled. Differential attenuation could be used to adjust for subtle differences in material density. The total

\footnotetext{
${ }^{8}$ See the following reference for a detailed discussion of this use of the Tl-208 gamma rays: R.B. Oberer, L.G. Chiang, M.J. Norris, C.A. Gunn, D.R. Eblen, "Determination of Uranium Concentration and Attenuation Correction in Dense Highly Enriched Uranium (HEU) Material by the Comparison of Gamma Rays from Tl-208," 49th Annual Meeting of the Institute of Nuclear Materials Management (INMM) 13-17 July 2008 Nashville, Tennessee.
} 
Y/EN- 8311

December 2009

quantity of the isotope would be determined by multiplying this concentration by the mass of the net contents.

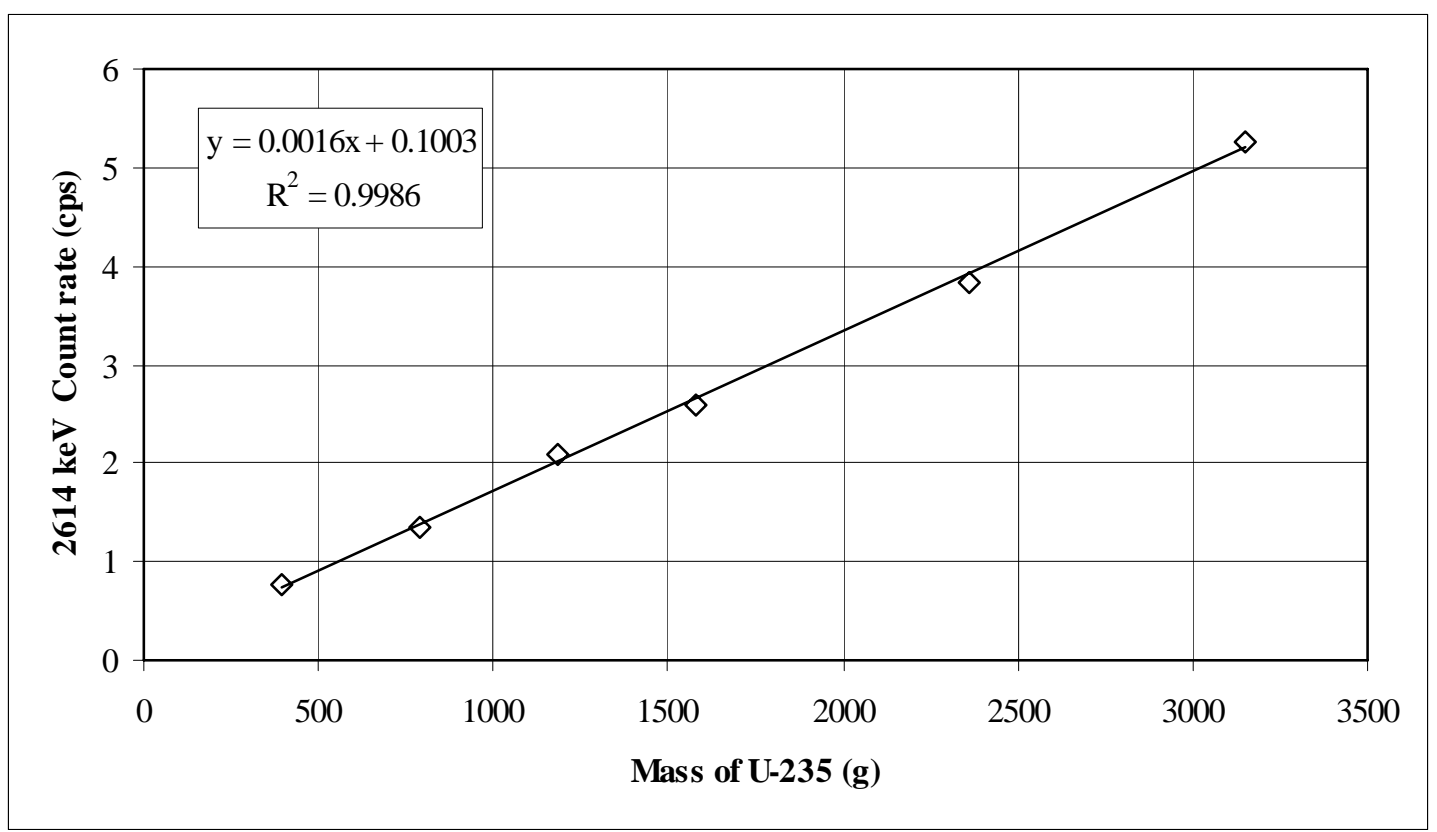

Figure 11. CRM-149 standards. Count rate (cps) in the 2614keV peak from Tl-208.

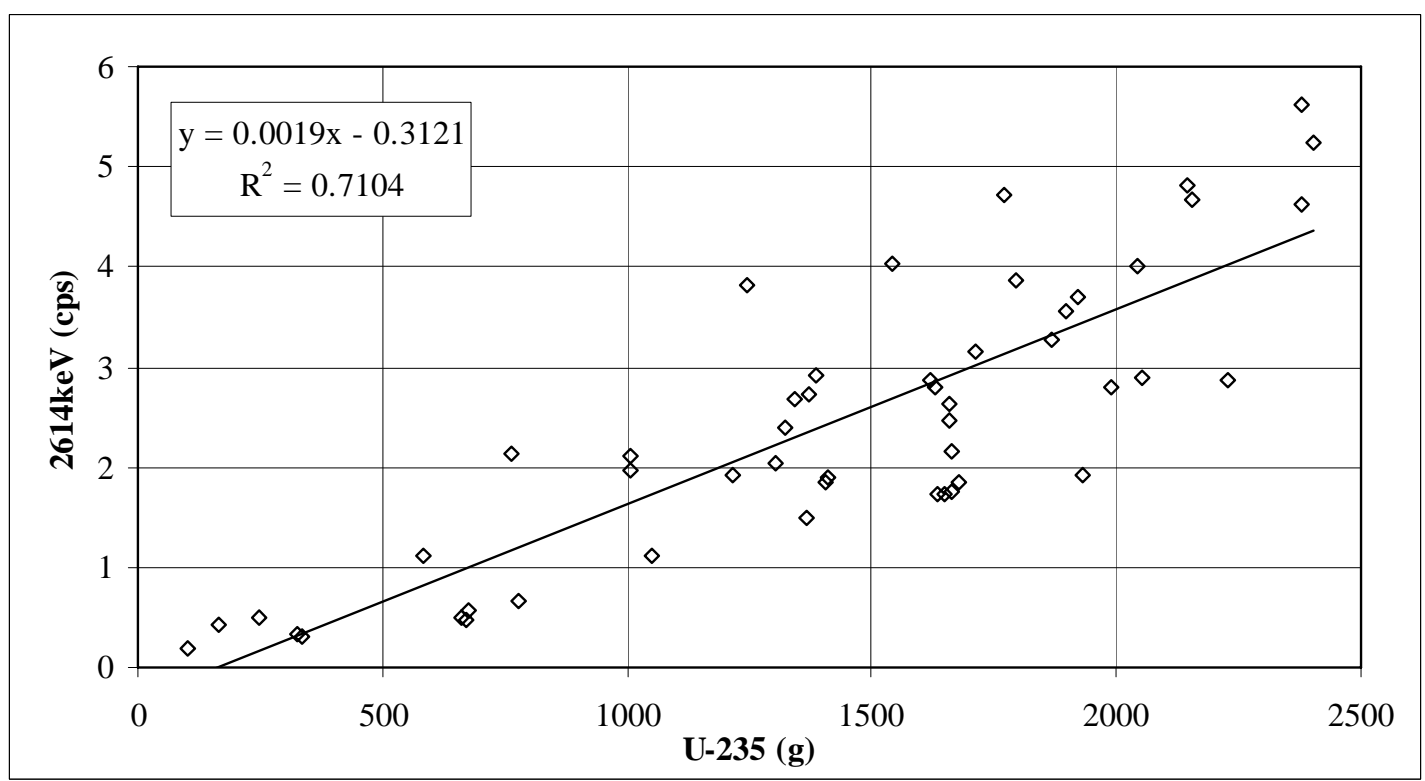

Figure 12. LANL-45 material. Count rate (cps) in the 2614keV peak from Tl-208.

Another approach which was tried is to calibrate on the $2614 \mathrm{keV}$ gamma ray alone. This would work very well for the CRM-149 material as shown in Figure 11. However, when applied to the LANL-45 material as shown in Figure 12, the results are approximate at best. The results for the CRM-149 material is probably better than expected. However, this material came from a single well blended batch of HEU. The LANL-45 material is 
Y/EN- 8311

December 2009

probably worse than is typically seen, but numerous batches and varying enrichments are involved.

\section{Conclusion}

The HPGe measurement of grams of U-235 was more accurate than the AWCC measurement which was precise but biased low by almost $25 \%$. This bias in the AWCC was perplexing because the calibration standards were similar to the unknowns. The only significant difference was in the diameter of the container. The CRM-149 standards were 4.88 inches in diameter whereas the LANL-45 unknowns were 4.00 inches in diameter. During operation the AWCC was observed to vary greatly from sample position. Although these small changes in geometry had a significant effect on the AWCC results, differences between the LANL-45 unknowns had little effect. The LANL-45 unknowns differed significantly in enrichment and fill height.

With the use of differential attenuation to adjust for the unknown density of the material contents, the HPGe produces accurate results. There was some randomness introduced partially from the differential attenuation adjustment. Two outliers produced by the HPGE measurement are unexplained. The HPGe measurement also measures the enrichment of the uranium. The enrichment results are both accurate and precise. 
Y/EN- 8311

December 2009

Table A-1. Detailed measurement results of the LANL-45 material by both AWCC and HPGe.

\begin{tabular}{|c|c|c|c|c|c|c|c|}
\hline \multirow{2}{*}{\multicolumn{4}{|c|}{ Declared Values }} & \multicolumn{4}{|c|}{ NDA Measured Values } \\
\hline & & & & AWCC & & HPGe & \\
\hline $\begin{array}{l}\text { Material } \\
\text { Item ID } \\
\text { Number }\end{array}$ & $\begin{array}{c}\text { Net } \\
\text { Weight } \\
\text { of } \\
\text { Material } \\
\text { (g) }\end{array}$ & $\begin{array}{c}\text { Weight } \\
\% \\
\text { U-235 }\end{array}$ & $\begin{array}{l}\text { U-235 } \\
\text { (g) }\end{array}$ & $\begin{array}{l}\mathrm{U}-235 \\
\text { (g) }\end{array}$ & $\begin{array}{l}\text { U-235 } \\
\text { (g) }\end{array}$ & $\begin{array}{l}\text { U-238 } \\
\text { (g) }\end{array}$ & $\begin{array}{c}\text { Weight \% } \\
\text { U-235 }\end{array}$ \\
\hline UOX18-22 & 2619.1 & 93.09 & 2045 & 1608 & 2080 & 138 & 93.8 \\
\hline UOX18-21 & 2774.9 & 93.09 & 2157 & 1758 & 2950 & 178 & 94.3 \\
\hline UOX18-20 & 2201.4 & 93.17 & 1711 & 1479 & 1920 & 123 & 94.0 \\
\hline UOX18-41 & 140.2 & 88.92 & 104 & 97 & 361 & 43 & 89.4 \\
\hline UOX18-40 & 2467.3 & 37.54 & 780 & 778 & 677 & 1140 & 37.3 \\
\hline UOX18-39 & 2092.2 & 37.57 & 661 & 671 & 581 & 956 & 37.8 \\
\hline UOX18-18 & 2464.7 & 93.10 & 1922 & 1638 & 2350 & 148 & 94.1 \\
\hline UOX18-17 & 2409.4 & 93.23 & 1896 & 1524 & 1800 & 122 & 93.7 \\
\hline UOX18-19 & 3067.1 & 93.10 & 2380 & 1836 & 2380 & 148 & 94.1 \\
\hline UOX18-12 & 2486.6 & 97.62 & 2052 & 1605 & 2310 & 39 & 98.4 \\
\hline UOX18-14 & 2696.3 & 97.66 & 2226 & 1845 & 1770 & 50 & 97.3 \\
\hline UOX18-13 & 2053.6 & 93.25 & 1618 & 1346 & 1620 & 104 & 94.0 \\
\hline UOX18-35 & 216.1 & 92.88 & 167 & 178 & 263 & 24 & 91.7 \\
\hline UOX18-34B & 1782.8 & 67.26 & 1006 & 863 & 949 & 450 & 67.8 \\
\hline UOX18-34A & 1786.9 & 67.26 & 1009 & 894 & 908 & 441 & 67.3 \\
\hline UOX18-38B & 2131.2 & 37.63 & 674 & 612 & 752 & 1140 & 39.7 \\
\hline UOX18-38A & 2127.6 & 37.63 & 672 & 680 & 522 & 943 & 35.6 \\
\hline UOX18-37 & 316.7 & 93.17 & 248 & 256 & 449 & 22 & 95.4 \\
\hline UOX18-42B & 1971.2 & 20.01 & 328 & 375 & 298 & 1070 & 21.8 \\
\hline UOX18-42A & 2028.9 & 20.01 & 338 & 402 & 202 & 973 & 17.2 \\
\hline UOX18-36 & 748.7 & 93.11 & 586 & 486 & 747 & 56 & 93.0 \\
\hline UOX18-32B & 2542.9 & 93.31 & 1990 & 1763 & 2050 & 133 & 93.9 \\
\hline UOX18-29B & 2147.7 & 93.22 & 1657 & 1300 & 1800 & 108 & 94.3 \\
\hline UOX18-33 & 1592.1 & 93.23 & 1246 & 1063 & 1370 & 90 & 93.8 \\
\hline UOX18-31 & 1544.1 & 93.05 & 1053 & 951 & 1190 & 73 & 94.2 \\
\hline UOX18-26 & 2845.2 & 93.18 & 2144 & 1811 & 2210 & 122 & 94.8 \\
\hline UOX18-25A & 2515.9 & 93.09 & 1952 & 1511 & & & \\
\hline UOX18-25B & 984.2 & 93.09 & 763 & 630 & 1010 & 59 & 94.4 \\
\hline UOX18-16 & 2559.0 & 93.23 & 2017 & 1624 & & & \\
\hline UOX18-15B & 2455.6 & 93.27 & 1835 & 1512 & & & \\
\hline UOX18-29A & 2113.6 & 93.22 & 1630 & 1297 & 1870 & 98 & 95.0 \\
\hline UOX18-15A & 2401.6 & 93.27 & 1794 & 1440 & 1950 & 103 & 95.0 \\
\hline UOX18-27 & 1902.9 & 93.07 & 1465 & 1218 & & & \\
\hline UOX18-28 & 2011.7 & 93.40 & 1579 & 1283 & & & \\
\hline UOX18-11 & 2022.6 & 97.60 & 1665 & 1271 & 1970 & 26 & 98.7 \\
\hline UOX18-1A & 2161.2 & 93.05 & 1680 & 1358 & 1860 & 108 & 94.5 \\
\hline UOX18-10A & 1713.8 & 97.61 & 1411 & 1210 & 1700 & 30 & 98.3 \\
\hline UOX18-2B & 1759.6 & 93.05 & 1368 & 1100 & 1620 & 99 & 94.2 \\
\hline UOX18-1B & 2135.7 & 93.05 & 1661 & 1326 & 1860 & 114 & 94.2 \\
\hline UOX18-3A & 2118.8 & 93.05 & 1648 & 1398 & 1970 & 126 & 94.0 \\
\hline
\end{tabular}


Y/EN- 8311

December 2009

Table A-1 cont'd. Detailed measurement results of the LANL-45 material by both AWCC and HPGe.

\begin{tabular}{|c|c|c|c|c|c|c|c|}
\hline \multirow{2}{*}{\multicolumn{4}{|c|}{ Declared Values }} & \multicolumn{4}{|c|}{ NDA Measured Values } \\
\hline & & & & AWCC & & HPGe & \\
\hline $\begin{array}{l}\text { Material } \\
\text { Item ID } \\
\text { Number }\end{array}$ & $\begin{array}{c}\text { Net } \\
\text { Weight } \\
\text { of } \\
\text { Material } \\
\text { (g) }\end{array}$ & $\begin{array}{c}\text { Weight } \\
\% \\
\text { U-235 }\end{array}$ & $\begin{array}{l}\text { U-235 } \\
\text { (g) }\end{array}$ & $\begin{array}{l}\text { U-235 } \\
\text { (g) }\end{array}$ & $\begin{array}{l}\text { U-235 } \\
\text { (g) }\end{array}$ & $\begin{array}{c}\mathrm{U}-238 \\
\text { (g) }\end{array}$ & $\begin{array}{c}\text { Weight \% } \\
\text { U-235 }\end{array}$ \\
\hline UOX18-2A & 2483.3 & 93.05 & 1931 & 1578 & 2280 & 139 & 94.3 \\
\hline UOX18-3B & 2099.6 & 93.05 & 1633 & 1350 & 1670 & 106 & 94.0 \\
\hline UOX18-10B & 1704.2 & 97.61 & 1404 & 1163 & 1730 & 28 & 98.4 \\
\hline UOX18-23 & 3091.2 & 93.09 & 2404 & 1903 & 2540 & 163 & 94.0 \\
\hline UOX18-24A & 2153.3 & 93.26 & 1658 & 1229 & 1840 & 102 & 94.7 \\
\hline UOX18-8B & 1786.3 & 93.17 & 1387 & 1146 & 1700 & 107 & 94.1 \\
\hline UOX18-9A & 2288.4 & 93.17 & 1768 & 1458 & 1710 & 90 & 95.0 \\
\hline UOX18-24B & 1692.4 & 93.26 & 1304 & 1076 & 1530 & 90 & 94.4 \\
\hline UOX18-30 & 2388.9 & 93.18 & 1868 & 1587 & 2020 & 117 & 94.5 \\
\hline UOX18-32A & 1551.9 & 93.31 & 1215 & 1056 & 1500 & 85 & 94.6 \\
\hline UOX18-7B & 1767.3 & 93.17 & 1372 & 1156 & 1640 & 90 & 94.8 \\
\hline UOX18-7A & 1730.8 & 93.17 & 1344 & 1127 & 1650 & 97 & 94.5 \\
\hline UOX18-9B & 1995.4 & 93.17 & 1542 & 1201 & 1360 & 94 & 93.5 \\
\hline UOX18-8A & 1702.2 & 93.17 & 1322 & 1115 & 1280 & 89 & 93.5 \\
\hline
\end{tabular}

